\title{
PÓS-MODERNIDADE, MAL-ESTAR, VIOLÊNCIA: UMA LEITURA DE MARIA LAURINDA RIBEIRO DE SOUZA
}

\author{
Post-modernity, psychoanalysis and violence: \\ an interpretation of Maria Laurinda Ribeiro de Souza
}

\author{
Igor Zanoni Constant Carneiro Leão* \\ Demian Castro** $^{* *}$
}

SOUZA, Maria Laurinda Ribeiro de. Violência. 1. ed. São Paulo: Casa do Psicólogo, 2005. 154 p. (Coleção Clínica Psicanalítica).

Inúmeros pensadores da área de humanidades têm trabalhado o tema de uma crise nos laços de sociabilidade constitutivos de aspectos centrais nas sociedades avançadas. Frequentemente referem um mal-estar não apenas no sentido que Freud emprestou a esta expressão, mas no sentido de uma crise da cultura ou civilização moderna, apontando mesmo para uma nova etapa dessas sociedades, dita pós-moderna. Um desses autores, Zygmunt Bauman ${ }^{1}$, é bastante conhecido no Brasil por sua vasta pesquisa sobre temas cruciais, como o emprego, a mobilidade social, a violência e o crime, a fragilidade das relações humanas, as mudanças na sensibilidade religiosa e outros. Parece-nos, contudo, ser importante prestar atenção à voz de psicanalistas que trabalham temas afins do ponto de vista da clínica, na medida em que nela a voz das emoções é mais clara, enriquecendo a discussão. Neste texto, fazemos uma leitura de Violência, de Maria Lau-

\footnotetext{
Professor do Departamento de Economia da UFPR. Doutor em Economia pelo Instituto de Economia da Unicamp.

** Chefe do Departamento de Economia da UFPR. Doutor em Economia pelo Instituto de Economia da Unicamp.

1 BAUMAN, Z. Modernidade líquida. Rio de Janeiro: Jorge Zahar, 2001; BAUMAN, Z. Mal-estar da pós-modernidade. Rio de Janeiro: Jorge Zahar, 1998.
} 
rinda Ribeiro de $\mathrm{Souza}^{2}$, especialista neste assunto fundamental à ideia de mal-estar na cultura contemporânea.

Nossa autora é psicóloga e psicanalista, membro do Departamento de Psicanálise do Instituto Sedes Sapientiae, São Paulo, e professora do Curso de Psicanálise desse Instituto. O livro que resenhamos foi editado na coleção Clínica Psicanalítica, dirigida por Flávio Carvalho Ferraz, pela Casa do Psicólogo. A autora é dona de uma obra significativa em psicanálise, destacando-se seus livros por aplicações à realidade brasileira de temas como adolescência, violência e o espaço do hospital. O presente livro prolonga suas aplicações da psicanálise a questões sociais brasileiras na virada do século. O principal mérito do texto, a nosso ver, é o estudo de aspectos da realidade social brasileira que nos vêm por jornais e revistas de circulação relativamente ampla a partir da escuta na terapia e no trabalho psicanalítico.

Na verdade, o conceito de pós-modernidade não é pacífico. Muitos autores lembram que, a partir do século XVIII, a modernidade no ocidente se configura sobre o indivíduo, o mercado e a ciência aplicada à técnica. Atualmente, a lógica desses fundamentos se desenvolve no sentido de sua radicalização. Isto permite falar numa continuidade da modernidade, mas de qualquer modo também de uma crise em seu interior que se pode denominar hipermodernidade ou pós-modernidade - não importa, desde que saibamos o que queremos dizer.

A autora com que trabalhamos aqui aponta, seguindo Gilles Lipovetsky ${ }^{3}$, os seguintes sintomas do hipermoderno ou do excesso de modernidade, a saber, a fragilização dos indivíduos levando a uma série de sintomas, como o suicídio, ansiedade, depressão, medos diversos, por exemplo, de desastres ecológicos, da AIDS, do envelhecimento, do desemprego e do futuro. Nesse sentido, para Lyotard ${ }^{4}$ vivemos uma época de possibilidade de invenção fundamental diante de um mundo caótico, no qual acentuam-se o acesso à singularidade, à autonomia e ao desejo, mas ao mesmo tempo ao mal-estar que aparece no desamparo, nas incertezas, na insuficiência, na fragilização do eu e dos vínculos coletivos.

O conceito de mal-estar na civilização ou cultura - Freud não distingue entre estes dois termos, que englobam o saber humano necessário

SOUZA, M. L. R. Violência. São Paulo: Casa do Psicólogo, 2005.

LIPOVETSKY, G. La era del vacio. Barcelona: Anagrama, 1986.

LYOTARD, J-F. A condição pós-moderna. Lisboa: Gradiva, 1989. 
ao domínio da natureza e à satisfação de suas necessidades, bem como a regulamentação das relações dos homens entre eles e na repartição dos bens que podem ser conquistados - é uma marca inelutável na constituição dos homens e da cultura, como efeito de uma renúncia às pulsões, da culpabilidade, da luta entre a satisfação de seu narcisismo e os limites impostos pela natureza, pela fragilidade do seu corpo e pelas relações com os outros. Para Freud, os homens buscam a felicidade, mas só alcançam aproximações substitutivas bastante insatisfatórias, fazendo com que o objetivo de sua ação seja mais uma busca pela diminuição do desprazer do que a conquista do prazer.

A busca humana de autonomia se faz com angústia, mas esta também cria laços na direção do outro. Como afirma Maria Laurinda,

[...] as reações coletivas que se têm constituído como forma de protesto e de solidariedade às vítimas da violência e a implantação de instâncias que coíbam o uso dos dispositivos institucionais legítimos são um resgate possível dos laços sociais e da justiça; uma tentativa de lidar com o desamparo e recriar o poder de ação e de discurso dos homens comuns. Para que elas sejam possíveis é necessária uma outra ultrapassagem: a da posição narcísica e dos efeitos nefastos do individualismo. ${ }^{5}$

Tentando entender melhor esta passagem, lemos na autora que o narcisismo e o individualismo estão intimamente imbricados, e os excessos do narcisismo podem ser entendidos como uma resposta às demandas ideais da cultura, mas também como uma forma de lidar com o medo do sofrimento, da solidão e da morte tão exponenciados pelo capitalismo moderno. Este violou fortemente o indivíduo na medida em que este se torna crescentemente só, sem uma comunhão autêntica com outro e destituído de vínculos comunitários que lhe deem segurança. Para Freud, não é possível uma harmonia entre as forças pulsionais e as demandas da cultura, tornando o desamparo como condição estrutural do ser humano, ao mesmo tempo em que a pulsão da morte pressiona ainda mais o conflito entre indivíduo e cultura. ${ }^{6}$

6 FUCKS, B. B. Freud e a cultura. Rio de Janeiro: Zahar, 2007. 
Nesse sentido a violência provém da diluição dos dispositivos de controle dessas pulsões como a garantia da lei como instrumento de proteção e segurança, a manutenção de condições dignas de vida, o favorecimento do laço social com o outro e a oferta pela cultura de uma identificação modelar dada pela violência e o gozo imediato. Diante disto, é preciso retomar os laços sociais e buscar um outro discurso e uma outra prática que restaurem o valor do espaço público e da inclusão social. Ainda para Freud, a culpa é um elemento que estrutura a possibilidade de autonomia do sujeito e de sustentação da cultura, na medida em que controla os efeitos de uma perda do enlace erótico, uma vez que a culpa é uma articulação indissociável do amor e do ódio.

Na subjetividade moderna, a ausência da culpa é uma de suas marcas desenvolvidas pelo capitalismo, na medida em que incita o indivíduo a abster-se de questionar as implicações éticas de seus atos. Ultrapassar a culpa exige o perdão, o reconhecimento de uma dívida para com o outro, permitindo ir adiante da angústia e do desamparo sem nos perdermos nesta culpa.

A violência tem um rosto político e social. No Brasil, ela aparece desde logo na desigualdade que se percebe nas famílias brasileiras quando se considera o rendimento médio mensal, o nível de escolaridade, o número de crianças por família, as crianças e os adolescentes que trabalham. Uma em cada cinco famílias no país vive em situação de alta vulnerabilidade, atingindo especialmente as crianças e as famílias do semiárido com a desnutrição e a mortalidade infantil.

Ao mesmo tempo, o desemprego em todo o mundo encontra-se num nível muito alto, marcando metade da população mundial pela pobreza. No Brasil, os índices de desemprego e subemprego também são extremamente altos, bem como a ameaça do desemprego, criando um medo crônico de humilhação social. A escolaridade do brasileiro também vai mal. Quase $60 \%$ das crianças que atingem a quarta série não sabem ler ou leem muito mal, segundo o MEC. Os brasileiros têm baixo nível de escolaridade, especialmente entre negros e pardos, o que é crítico, já que a educação é o fator mais importante para a mobilidade social e que filhos de pais não escolarizados tendem a se manter no mesmo nível.

Se considerarmos as vítimas de homicídio, o país é um dos mais violentos do mundo, com cerca de 27 homicídios para cada cem mil habitantes contra menos de duas mortes para cada cem mil habitantes nos países 
desenvolvidos da Europa e da Ásia. Mais de 90\% desses homicídios foram causados por armas de fogo. Os jovens mortos de forma violenta fazem do Brasil um campeão de violência, especialmente nos bairros pobres, por exemplo, nas zonas leste e sul de São Paulo. Estes dados estão relacionados com a perda de espaço das relações de apoio mútuo, as associações comunitárias e a Igreja, diante da criminalidade organizada, do contrabando de armas e do tráfico de drogas. Contudo, é preciso não criminalizar a pobreza, mas, antes, pensar nela em termos de um risco para o futuro dessa geração de jovens.

A exclusão econômica e social não dá conta, porém, da violência através do crime organizado, dos crimes de "colarinho branco", das práticas arbitrárias da polícia, da corrupção dentro dos poderes públicos e do tecido social, a inércia burocrática e a ineficiência que impedem a ação da justiça. Há no país um quadro de patologia das instituições, com partidos políticos considerados não confiáveis, ao lado do Congresso e da Justiça. Aparecem como as mais confiáveis a Igreja, seguida pela Educação e pelos noticiários de TV, com as Forças Armadas surgindo em seguida, resíduo de uma percepção de guerra civil permanente ou um chamado à força das armas para debelar a violência.

Finalmente, a humilhação social marca o mundo dos pobres, que sentem a aversão, o desprezo e o racismo como um fenômeno ao mesmo tempo psicológico e político. A humilhação assume a forma de uma angústia, tolhendo os gestos, a imaginação e a fala do humilhado. Muitas crianças e adolescentes confinam-se a um lugar deteriorado, como os meninos de rua, os egressos da FEBEM, os favelados, os pobres, os que carregam o estigma de bandidos. Estes estigmas provocam a xenofobia, com a qual se tenta eliminar da vida ou da paisagem aqueles que incomodam. Em todos estes sentidos, as condições sociais e políticas são retratos da violência brasileira.

À guisa de um parêntese no texto que vamos lendo e reconfigurando, é importante deixar claro que as características centrais na psique humana, sua cisão e conflito inelutável, suas pulsões eróticas e agressivas, o narcisismo e o individualismo, entre outras, são reinscritas na cultura, de modo a fazer com que no homem já nada seja natural mas, antes, cultural. Assim, se a psicanálise pode ser um ponto de partida para pensar a cultura, como os escritos do próprio Freud deixam claro, também os estudos culturais, vale dizer, as humanidades, podem esclarecer o espaço e os limites 
da psique humana, sem desfigurar sua historicidade. Dentro de um espaço maior ou menor de liberdade, os seres humanos são filhos do seu tempo e lugar e exercem uma ação coletiva sobre estes, cultivando-os a partir de sua psique. Também os constrangimentos ao homem, como aqueles colocados pelo capitalismo em suas diversas configurações geográficas e temporais, são desafios à sua psique que requerem respostas diversas dos homens como sujeitos individuais e coletivos. Nesse sentido, suas emoções não estão soltas, mas imbricadas em sua vida concreta, na medida em que esta suscita respostas. Isto recoloca a necessidade de pensar as conexões de sentido entre o econômico, o político, o cultural, o social, porque todas estas instâncias se articulam para falar do tempo e do lugar dos seres humanos, de sua vida e sua história. Estas observações se articulam com uma citação de Radmila Zygouris feita pela autora que estamos lendo: "Não levar em conta a incessante contaminação da psique pelo coletivo significa querer negar o múltiplo no próprio interior do sujeito e sua necessidade narcísica e vital de exercer um poder sobre o mundo".

Esta citação introduz a parte mais original e interessante do livro de Maria Laurinda, a das suas histórias clínicas ligadas à violência. Para ela, as cenas violentas do dia a dia se entremeiam com o medo e as angústias íntimas, e os sonhos repetem o trauma das cenas vividas e procuram dar-lhe outros caminhos. Sem repetir o relato dessas histórias, elas contam o medo de que as notícias de violência próximas ao analisante possam se repetir com eles. $\mathrm{O}$ meio ambiente atua tranquilizando e colocando um limite aos medos internos, mas hoje o terror é internalizado e alimenta os medos mais primários inscritos no mundo tão cruel. Alguns conseguem uma aproximação com a fragilidade e o desamparo, mas terminam percebendo que a violência pode acontecer com qualquer um e, portanto, consigo, num confronto inevitável com a vulnerabilidade. Não há, ao mesmo tempo, nenhum lugar em que possa dar queixa da violência e registrar as cenas traumáticas que se tornam corriqueiras é inútil.

$\mathrm{O}$ sequestro, como em sua forma de sequestro relâmpago, atinge o que é mais radical para o sujeito, seu corpo e sua vida, levando-o a sentir a proximidade da morte, o desamparo, a impossibilidade de defesa diante

7 ZYGOURIS, R. Pulsões da vida. São Paulo: Escuta, 1999, citado por SOUZA, M. L. R. Op. cit., nota 2, p. 111. 
de uma possível demanda de entrega absoluta. Cenas assim prefiguram outras no futuro e o atingido teme sair à rua, sente como suspeitos pessoas próximas no momento de estacionar o carro, redobra as tentativas de cuidar, a posteriori, o que não pode ser prevenido.

As cenas de tortura, por sua vez, levam, em primeiro lugar, à aniquilação dos valores e convicções do indivíduo, provocam uma desorganização de sua relação consigo mesmo e com o mundo, finalmente exigem uma resolução emocional dessa experiência limite. $\mathrm{O}$ excesso de violência, em todas essas causas, provoca uma ameaça da demolição do eu e da imagem do próprio corpo, surgindo o medo de sair de casa, a ansiedade, os problemas de memória e de atenção. Depois, surgem os pesadelos, a insônia, a paranoia de perseguição, o falso reconhecimento do sequestrador em todos os lugares e mesmo uma incapacitação para o trabalho e o convívio social. Todavia, muitas vezes as experiências se transformam em dor. É o momento em que o corpo tenta se resgatar, recompor sua integridade ameaçada, fazer um apelo à presença do outro, de seus cuidados e de sua proteção, ou seja, tudo que faltou na experiência limite do sequestro.

A autora examina ainda situações do cotidiano aparentemente inofensivas, mas que agridem fortemente o sujeito por sua violência. Sabe-se que há uma relação significativa entre o comportamento violento e o número de horas que um sujeito adolescente ou jovem adulto permanece diante da televisão. Entretanto, sair da submissão à TV pode colocar a insatisfação com o que somos e a intolerância com as contradições da vida.

Crescem entre os jovens os sintomas de uma apatia e profunda indiferença para com o mundo, insensibilizando o sujeito diante das emoções. O que caracteriza o nosso tempo é o apelo da mobilidade intensa e da ação contínua, levando a uma crise do entusiasmo e da vontade, criando dificuldades para se comover com o mundo e agir em eu interior. A indiferença e a apatia surgem como uma forma de se defender do desamparo a que se veria exposto se pudesse perceber o que vive. O excesso de cenas de pobreza, de solicitações nas paradas no farol, dos riscos de manter os vidros e os olhos abertos gera uma situação emocional de indiferença e de ser inexistente para os outros. Fechar os olhos para não ver não garante imunidade e se sente a impossibilidade de uma ação eficaz diante da crueldade do real.

Segundo a autora, 
O medo presentifica a fragilidade, a vulnerabilidade e o desamparo, e pode levar a uma demanda de proteção onipotente. É por essa brecha que se infiltram as legitimações de práticas repressivas violentas e os abusos dos poderes autoritários. Mas o medo, como sinal, quando não leva à paralisia, pode ser uma forma de se manter alerta, de criar dispositivos de proteção e enlaces com forças coletivas menos destrutivas. ${ }^{8}$

A apatia representa um ataque ao eu que leva a uma redução ao mínimo das emoções e do desejo. O medo, nesse sentido, aparece como uma revolta e uma possibilidade de mobilização. Experimentar o ódio e o sofrimento pode se tornar uma condição de sobrevivência e uma forma de não cair na insensibilidade afetiva e no imobilismo.

As aberturas contra as situações acima exigem a tolerância com a diferença, a capacidade de viver a experiência do que é estrangeiro, permitindo, pelo surgimento da compaixão, enfrentar a crueldade, o racismo, a xenofobia, a violência contra os outros. Enfrentar a violência resultante da excessiva agressividade, preservando o prazer da vida, exige, sobretudo, falar, isto é, resgatar a memória, produzir narrativas, contar aos outros, registrar, construir histórias e laços sociais. A nosso ver, esta é uma possibilidade que a psicanálise oferece na medida em que o sujeito pode se encontrar num espaço partilhado e protegido necessário à sua reconstrução libidinal.

Recebido em julho de 2010. Aprovado em junho de 2011. 